\title{
Cross-linking of sodium caseinate-structured emulsion with transglutaminase alters postprandial metabolic and appetite responses in healthy young individuals
}

\author{
Kristiina R. Juvonen ${ }^{1 *}$, Adam Macierzanka ${ }^{2,3}$, Martina E. Lille ${ }^{4}$, David E. Laaksonen ${ }^{5,6}$, \\ Hannu M. Mykkänen ${ }^{1}$, Leo K. Niskanen ${ }^{7,8}$, Jussi Pihlajamäki ${ }^{1,9}$, Kari A. Mäkelä ${ }^{10}$, Clare E. N. Mills ${ }^{2,11}$, \\ Alan R. Mackie ${ }^{2}$, Paul Malcolm ${ }^{12}$, Karl-Heinz Herzig ${ }^{10,13}$, Kaisa S. Poutanen ${ }^{1,4}$ and Leila J. Karhunen ${ }^{1,9}$ \\ ${ }^{1}$ Department of Clinical Nutrition, Institute of Public Health and Clinical Nutrition, University of Eastern Finland, \\ P.O. Box 1627, 70211 Kuopio, Finland \\ ${ }^{2}$ Institute of Food Research, Norwich NR4 7UA, UK \\ ${ }^{3}$ Department of Fats and Detergents Technology, Faculty of Chemistry, Gdansk University of Technology, \\ Narutowicza 11/12, 80-952 Gdansk, Poland \\ ${ }^{4}$ VTT Technical Research Centre of Finland, 02150 Espoo, Finland \\ ${ }^{5}$ Internal Medicine, Institute of Clinical Medicine, Kuopio University Hospital, 70211 Kuopio, Finland \\ ${ }^{6}$ Department of Physiology, Institute of Biomedicine, University of Eastern Finland, 70211 Kuopio, Finland \\ ${ }^{7}$ Finnish Medicines Agency Fimea, Helsinki 00280, Finland \\ ${ }^{8}$ Faculty of Health Sciences, School of Medicine, University of Eastern Finland, Kuopio 70211, Finland \\ ${ }^{9}$ Department of Clinical Nutrition and Obesity Center, Kuopio University Hospital, 70211 Kuopio, Finland \\ ${ }^{10}$ Division of Physiology and Biocenter of Oulu, Institute of Biomedicine, Oulu University, 90014 Oulu, Finland \\ ${ }^{11}$ Manchester Interdisciplinary Biocentre, University of Manchester, Manchester M1 7DN, UK \\ ${ }^{12}$ Norfolk and Norwich University Hospital, Colney Lane, Norwich, UK \\ ${ }^{13}$ Medical Research Center Oulu and Oulu University Hospital, Oulu, Finland
}

(Submitted 5 May 2014 - Final revision received 28 March 2015 - Accepted 21 April 2015 - First published online 10 July 2015)

\section{Abstract}

The physico-chemical and interfacial properties of fat emulsions influence lipid digestion and may affect postprandial responses. The aim of the present study was to determine the effects of the modification of the interfacial layer of a fat emulsion by cross-linking on postprandial metabolic and appetite responses. A total of fifteen healthy individuals (26.5 (SEM 6.9) years and BMI 21.9 (SEM $2 \cdot 0) \mathrm{kg} / \mathrm{m}^{2}$ ) participated in a cross-over design experiment in which they consumed two isoenergetic (1924 kJ (460 kcal)) and isovolumic (250 g) emulsions stabilised with either sodium caseinate (Cas) or transglutaminase-cross-linked sodium caseinate (Cas-TG) in a randomised order. Blood samples were collected from the individuals at baseline and for $6 \mathrm{~h}$ postprandially for the determination of serum TAG and plasma NEFA, cholecystokinin (CCK), glucagon-like peptide 1 (GLP-1), glucose and insulin responses. Appetite was assessed using visual analogue scales. Postprandial TAG and NEFA responses and gastric emptying (GE) rates were comparable between the emulsions. CCK increased more after the ingestion of Cas-TG than after the ingestion of Cas $(P<0 \cdot 05)$, while GLP-1 responses did not differ between the two test emulsions. Glucose and insulin profiles were lower after consuming Cas-TG than after consuming Cas $(P<0 \cdot 05)$. The overall insulin, glucose and CCK responses, expressed as areas above/under the curve, did not differ significantly between the Cas and Cas-TG meal conditions. Satiety ratings were reduced and hunger, desire to eat and thirst ratings increased more after the ingestion of Cas-TG than after the ingestion of Cas $(P<0 \cdot 05)$. The present results suggest that even a subtle structural modification of the interfacial layer of a fat emulsion can alter the early postprandial profiles of glucose, insulin, CCK, appetite and satiety through decreased protein digestion without affecting significantly on GE or overall lipid digestion.

Key words: Emulsion: Cross-linking: Transglutaminase: Digestion: Gastric emptying: Satiety: Gastrointestinal hormones

Abbreviations: Cas, sodium caseinate; Cas-TG, transglutaminase-cross-linked sodium caseinate; CCK, cholecystokinin; GE, gastric emptying; GLP-1, glucagon-like peptide 1; Na-Cas, sodium caseinate; TG, transglutaminase.

*Corresponding author: Dr K. R. Juvonen, fax +358 17162 792, email kristiina.juvonen@uef.fi 
Dietary fat plays a central role in human diet. As the most energy-dense macronutrient, it has a marked effect on the energy content of our diet; however, it also controls postprandial metabolism and appetite-related signalling mechanisms ${ }^{(1,2)}$. Dietary fat is often incorporated into foods in the form of protein-stabilised lipid emulsions, which, in turn, comprise a major part of many processed food formulations $^{(3,4)}$.

Besides providing nutritional advantages to food products, dietary proteins are also excellent emulsifiers. Various protein types are frequently used as stabilising agents in emulsions to control food form, texture, structure and even lipid bioavailability, i.e. the digestion and absorption kinetics of nutrients during the postprandial phase ${ }^{(3,5)}$. In addition, lipid bioavailability from emulsions can be either increased or decreased by modifying the interfacial properties of stabilising proteins either physico-chemically or enzymatically ${ }^{(3,5)}$.

Enzymatic cross-linking of food biopolymers, including proteins, is an attractive and feasible modification option due to the specificity of enzymes and the requirement of mild reaction conditions ${ }^{(6)}$. Modification with cross-linking enzymes such as transglutaminase (TG) has been extensively used to change the functionality of proteins and thereby to improve the textural quality, stability and function of protein-based food products ${ }^{(6-8)}$. Ultimately, the way the stabilising proteins are modified plays a key role in the digestion and absorption kinetics of lipids, and thereby determines the effects on the critical factors affecting postprandial metabolic and appetite responses ${ }^{(3,5)}$. Nevertheless, several previous investigations have focused primarily on the lipolysis of emulsified fats/oils ${ }^{(9-11)}$, despite the fact that proteolysis, i.e. the breakdown of the stabilising protein, precedes lipolysis in systems if exposed to physiological conditions prevailing in the human gastrointestinal tract.

Several recent studies ${ }^{(12-17)}$ have demonstrated that the physico-chemical properties of emulsions as well as modification of factors affecting lipid behaviour in the gastrointestinal tract have marked effects on postprandial physiology and appetite sensations. For example, Marciani et al. ${ }^{(14)}$ demonstrated that acid-instable fat emulsions in the stomach lead to rapid layering of fat in the gastric lumen with accelerated gastric emptying (GE), lower cholecystokinin (CCK) levels, reduced gall bladder contraction, and increased postprandial appetite compared with acid-stable fat emulsions. Furthermore, Seimon et al. ${ }^{(16)}$ showed that increased droplet size of lipid emulsion not only affected postprandial physiological functions, e.g. diminished suppression of antroduodenal motility, but was also associated with attenuation of the stimulation of serum TAG, CCK and peptide YY as well as with reductions in the suppression of hunger and energy intake. However, many of the previous studies have used non-protein-based stabilisers, and, currently, very limited knowledge is available regarding the postprandial digestibility and effects of emulsions stabilised with enzymatically modified proteins in humans.

Therefore, to improve the still limited understanding of the effects of physico-chemical properties of food emulsions in the human digestion process, we investigated the effects of sodium caseinate-stabilised emulsion structured with TG on postprandial metabolic, hormonal and appetite responses in healthy young individuals. We hypothesised that cross-linking of sodium caseinate would decrease the breakdown of the TG-cross-linked emulsion, and thereby delay the rate of protein and lipid digestion. This would subsequently result in delayed postprandial serum TAG responses, increased CCK, glucagon-like peptide 1 (GLP-1) and satiety responses, and potentially increased GE rates.

\section{Participants and methods}

We conducted two postprandial studies: (1) a metabolic study in which appetite, metabolic and hormonal responses were assessed, and (2) a complementary gastric retention study in which GE rate was determined. Both studies used a single-blind, randomised, cross-over design.

These studies were conducted according to the guidelines laid down in the Declaration of Helsinki, and all procedures involving human participants were approved by the Ethical Committee of the Northern Savo Hospital District (Finland) (metabolic study) and the Essex 1 Research Ethics Committee (UK) (MRI study). Written informed consent was obtained from all participants.

\section{Metabolic study}

Participants. A total of fifteen healthy, normal-weight individuals (fourteen female and one male) participated in the metabolic study at the Department of Clinical Nutrition at the University of Eastern Finland (Table 1). Volunteers were recruited via Intranet announcements and newspaper advertisements in the Kuopio city area.

Before participating in the study, volunteers were interviewed about their medical history, dietary habits and physical activity. Exclusion criteria were as follows: any food allergies or intolerances; breakfast skipping; marked changes in diet or exercise routine during the past year to lose weight; medication (except oral contraceptives); smoking. The Three-Factor Eating Questionnaire ${ }^{(18)}$ was used to screen volunteers with abnormal eating behaviour. During the screening

Table 1. Characteristics of the study participants in the metabolic study (Mean values with their standard errors; $n 15^{\star}$ )

\begin{tabular}{lrl}
\hline Characteristics & Mean & \\
\hline Age (years) & 26.5 & 1.8 \\
Weight $(\mathrm{kg})$ & 63.2 & 2.2 \\
Height $(\mathrm{m})$ & 1.7 & 0.02 \\
BMI $\left(\mathrm{kg} / \mathrm{m}^{2}\right.$ ) & 21.9 & 0.5 \\
Systolic blood pressure $(\mathrm{mmHg})$ & 113.9 & 1.8 \\
Diastolic blood pressure $(\mathrm{mmHg})$ & 72.2 & 1.3 \\
Three-Factor Eating Questionnaire & & \\
$\quad$ Cognitive restraint of eating (factor 1) & 7.5 & 0.7 \\
Disinhibition (factor 2) & 3.5 & 0.5 \\
Hunger (factor 3) & 2.5 & 0.3 \\
\hline
\end{tabular}

${ }^{*}$ Female, $n$ 14; male, $n 1$. 
Table 2. Characteristics of the study participants in the gastric retention study

(Mean values with their standard errors; $n 4$ male)

\begin{tabular}{lrl}
\hline Characteristics & Mean & SEM \\
\hline Age (years) & 39.0 & 4.0 \\
Weight $(\mathrm{kg})$ & 83.6 & 3.2 \\
Height $(\mathrm{m})$ & 1.8 & 0.03 \\
BMI $\left(\mathrm{kg} / \mathrm{m}^{2}\right)$ & $25 \cdot 2$ & 0.5 \\
Systolic blood pressure $(\mathrm{mmHg})$ & 129.0 & 2.3 \\
Diastolic blood pressure $(\mathrm{mmHg})$ & 74.0 & $2 \cdot 2$ \\
\hline
\end{tabular}

visit, study procedure and measurements were individually explained to the volunteers to familiarise them with the study protocol and reduce potential misunderstanding.

Study design. All participants tested the two emulsions in consecutive weeks, with more than $3 \mathrm{~d}$ between the individual study days. Participants were instructed to maintain their habitual diet and exercise routines as constant as possible, refrain from heavy exercise on the day before the study visit, and avoid alcohol consumption for $2 \mathrm{~d}$ before each test day. Participants were requested to arrive the same way (e.g. walking, cycling, car or bus) for every laboratory visit and to avoid extra physical stress before the beginning of the visit. At the beginning of the two study days, participants were weighed, and their alcohol consumption and physical activity during the previous day were checked by an interview.

All the study visits began in the morning after a $10-12 \mathrm{~h}$ fast. In the beginning of the study period, participants consumed one of the chilled test emulsions between 07.45 and 08.15 hours along with $100 \mathrm{ml}$ tap water: an oil-in-water emulsion stabilised with either (1) sodium caseinate (Cas) or (2) transglutaminase-cross-linked sodium caseinate (Cas-TG) in a randomised order (Table 3).

Blood samples were drawn from the participants for the determination of plasma glucose, insulin, NEFA, CCK, GLP-1 and serum TAG responses using an indwelling cannula placed in the forearm $10 \mathrm{~min}$ before the baseline blood sampling. Venous samples were collected at baseline and at 15, 30, 45, 60, 90, 120, 180, 240, 300 and $360 \mathrm{~min}$ after the ingestion of the test emulsions. Appetite ratings were collected at concomitant time points immediately after the blood sampling. Participants were requested to avoid any extra physical activity and stay in a sitting position during the study period.

\section{Gastric retention study}

The MRI study conducted in Norwich, UK was designed to assess the differences in GE between the two test emulsions. The study included four male volunteers aged between 20 and 50 years with BMI between 19 and $30 \mathrm{~kg} / \mathrm{m}^{2}$ (Table 2). Exclusion criteria were similar to those given in the metabolic study, and screening was performed in a similar way at the Human Nutrition Unit of Institute of Food Research, IFR (Table 3).

Each volunteer visited the study centre on two occasions, at least $7 \mathrm{~d}$ apart, and consumed one of the test emulsions on each occasion. The order in which the emulsions were consumed was randomly allocated. All volunteers consumed all of the test emulsions within $5 \mathrm{~min}$. On each study day, volunteers were asked to eat their breakfast at home (before 09.00 hours). They were allowed to drink as much water as they needed but only until 10.00 hours. After this time, no further consumption was allowed. MRI images of the upper abdomen of the volunteers were taken $10 \mathrm{~min}$ before consumption of the test products and at 5, 25, 45, 65, 85, 105, 125, 145, 165 and $185 \mathrm{~min}$ after ingestion. The gastric content of the volunteers was determined using a conventional $1.5 \mathrm{~T}$ MRI scanner (Siemens Avanto 1.5T). Imaging used a TRUFISP (true fast imaging with steady-state precession) protocol developed to scan the stomach in a breath-hold of the order of 15-25s depending on the fullness of the stomach (repetition time/ echo time $3.5 / 1.5 \mathrm{~ms}$, field of view $24 \times 32 \mathrm{~cm}$, matrix $154 \times 256$ and slice thickness $0.5 \mathrm{~cm}$ ). This yields contiguous $5 \mathrm{~mm}$ axial slices through the stomach, enabling calculation of the total stomach volume. Both transverse and coronal images were acquired in order to ensure that the gastric volume could be accurately defined. Total volumes of gastric contents (excluding gas) and the volumes of layers formed as a result of sedimentation were determined at each time point using freehand tracings of the region of interest around the stomach contents/layers for each slice, and from this, the total stomach volume was calculated. Each scan took about $5 \mathrm{~min}$, and between scans, the volunteers underwent minimal physical movement and remained seated close to the scanner.

\section{Preparation of the test products}

The preparation of the test emulsions used in these studies was done using a similar protocol in each study site. Sodium caseinate (Na-Cas) solution for the emulsions was prepared by dissolving $3.8 \mathrm{~g}$ of $\mathrm{Na}$-Cas powder $(85.5 \%$ protein) into boiling tap water (total $250 \mathrm{~g}$ ) to obtain a protein stock $(c=13 \mathrm{mg} / \mathrm{g})$. For emulsion preparation, $207.7 \mathrm{~g}$ of the cooled protein stock and $54 \mathrm{~g}$ of rapeseed oil (Keiju Rapeseed

Table 3. Composition of the test emulsions used in the studies ${ }^{\star}$

\begin{tabular}{lrr}
\hline & Cas & Cas-TG \\
\hline Portion size (g) & 250.0 & 250.0 \\
Energy & 1923.0 & 1923.0 \\
$\quad$ kJ & 460.0 & 460.0 \\
kcal & 7.7 & 7.7 \\
Energy density (kJ/g) & & \\
Protein $\dagger$ & 2.5 & 2.5 \\
g & 2.2 & 2.2 \\
E\% & 0.0 & 0.0 \\
Carbohydratest & 0.0 & 0.0 \\
g & & \\
Eat & 50.0 & 50.0 \\
$\quad$ g & 97.8 & 97.8 \\
E\% & & \\
\hline
\end{tabular}

Cas, non-cross-linked sodium caseinate emulsion; Cas-TG, transglutaminasecross-linked sodium caseinate emulsion; E\%, percentage of energy.

* Ingested with $100 \mathrm{ml}$ tap water.

†Percentage of total energy content. 
Oil; Raisio plc) were added into a plastic mill cup and mixed with a high-speed blender (Kenwood BL450) under conditions that minimised the formation of protein-stabilised foam. The system was first sheared for $30 \mathrm{~s}$ at a low speed, and then stopped for $30 \mathrm{~s}$ and sheared again for $30 \mathrm{~s}$ at a high speed. After another $30 \mathrm{~s}$ break, shearing was repeated at a high speed for $30 \mathrm{~s}$.

Immediately after mixing, $242.3 \mathrm{~g}$ of freshly prepared emulsion were transferred into a glass decanter, covered with parafilm and placed in an incubator $\left(27.5^{\circ} \mathrm{C}, 50 \mathrm{rpm}\right)$ for $10-15 \mathrm{~min}$. In the case of TG (94\% maltodextrin + lactose, $5 \%$ moisture and $1 \%$ protein, TG powder, Activa MP; Ajinomoto Foods Europe SAS) cross-linked emulsion, $5 \mathrm{~g}$ of the TG stock (1:10 (w/w), microbial TG in tap water) were added into the emulsion and completed with $2 \cdot 7 \mathrm{~g}$ of tap water to obtain a final weight of $250 \mathrm{~g}$ (final enzyme:protein ratio $500 \mathrm{nkat} / \mathrm{g}$ in emulsion). The emulsion stabilised with non-cross-linked Na-Cas was made up in a similar manner but with heat-inactivated $\left(100^{\circ} \mathrm{C}, 30 \mathrm{~min}\right) \mathrm{TG}$ stock. The emulsions were gently mixed for $10-20 \mathrm{~s}$, covered and placed again in the incubator, where incubation was carried out for $3 \mathrm{~h}\left(27.5^{\circ} \mathrm{C}, 50 \mathrm{rpm}\right)$. Afterwards, the emulsions were transferred to a fridge to continue incubation at $5^{\circ} \mathrm{C}$ for $14 \mathrm{~h}$ (static conditions). The final composition of the emulsions was $20 \mathrm{wt} \%$ rapeseed oil and $80 \mathrm{wt} \%$ aqueous phase containing $\mathrm{Na}$-Cas (1 wt $\%$ Na-Cas in final emulsion).
Just before serving, the emulsions were gently stirred with a spoon for about $5-10 \mathrm{~s}$ to redisperse droplets from the cream layer.

\section{Characterisation of the test products}

The test products were characterised in terms of their oil droplet size distribution, the viscosity of the emulsion and the extent of protein cross-linking. Emulsion droplet size distribution was determined using an LS-230 laser diffraction particle sizer (Beckman Coulter Limited). The measurements were made for three replicate emulsions obtained under the same conditions. Viscosity of the emulsion samples was measured using an AR2000 rheometer (TA Instruments) equipped with the coaxial cylinder geometry $(15 \mathrm{~mm}$ outer diameter, $12 \mathrm{~mm}$ inner diameter). The emulsion $(13 \mathrm{ml})$ was introduced into the measuring cell of the rheometer, and a viscosity ramp test carried out at $23 \pm 0 \cdot 1^{\circ} \mathrm{C}$ for a shear rate being increased from 0.01 to 500 per s over $15 \mathrm{~min}$. The extent of $\mathrm{Na}$-Cas cross-linking was evaluated by SDS-PAGE. All chemicals and gels used for the SDS-PAGE analysis were purchased from Invitrogen Limited. Aliquots $(8 \mu \mathrm{l})$ of emulsions taken after incubation with or without TG were mixed with $5 \mu \mathrm{l}$ NuPAGE reducing agent, $12.5 \mu \mathrm{l}$ NuPAGE LDS sample buffer $(4 \times)$ and $35 \mu l$ phosphate buffer (used as a diluting agent). They were additionally mixed with $5 \mu$ l of $5 \%(\mathrm{w} / \mathrm{v})$ SDS solution (Sigma) in order to displace the

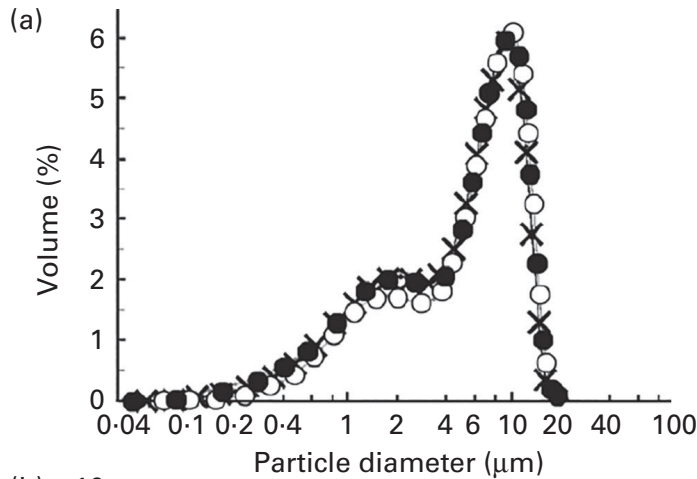

(c)
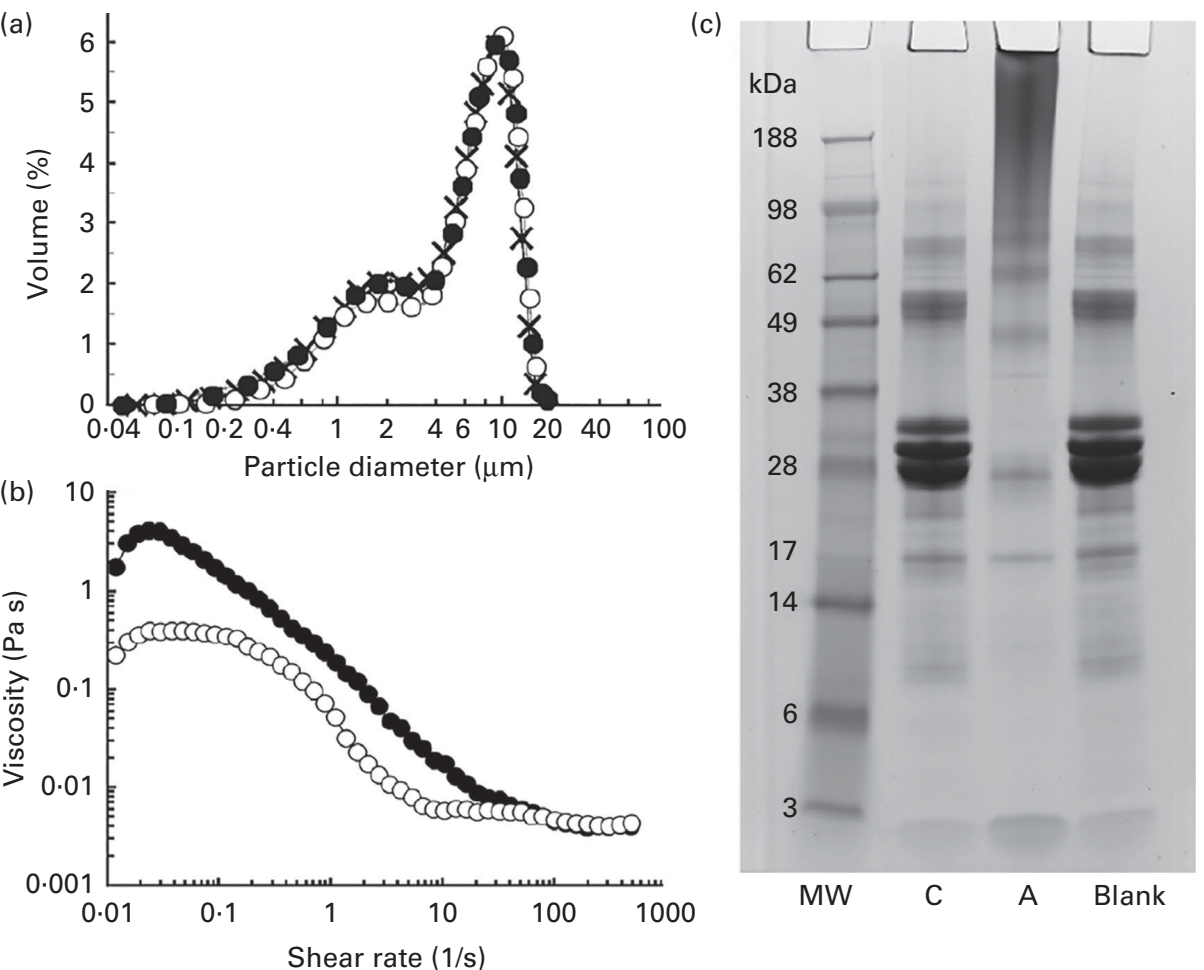

Fig. 1. (a) Droplet size distributions of sodium caseinate (Na-Cas)-stabilised emulsions: $\times$, Freshly prepared emulsion; $\bullet$, emulsion after incubation with transglutaminase (TG); $O$, emulsion after incubation with heat-inactivated TG. (b) Viscosity profiles of the emulsions as determined after incubation with TG ( $\bullet$ ) or heat-inactivated TG $(O)$. (c) SDS-PAGE analysis (reducing conditions) of the protein patterns in the emulsions: C, control Na-Cas-stabilised emulsion after incubation with heat-inactivated TG; A, active sample where Na-Cas was cross-linked with TG; Blank, Na-Cas-stabilised emulsion after incubation without TG (see text for the incubation conditions); MW, molecular-weight standard. 
(a)

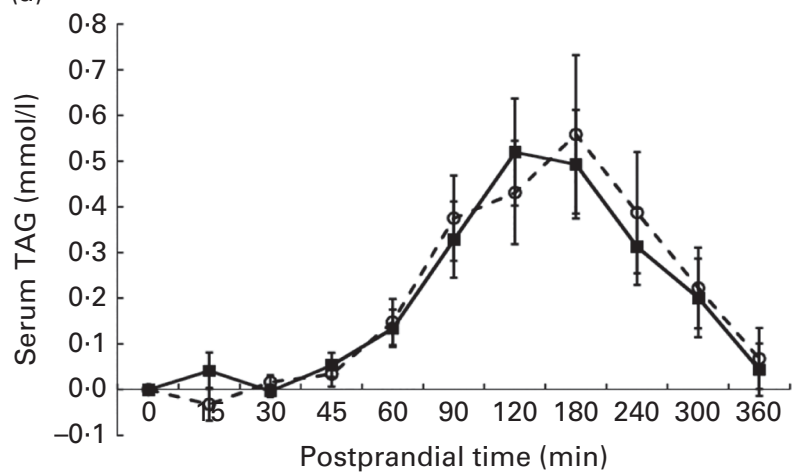

(c)

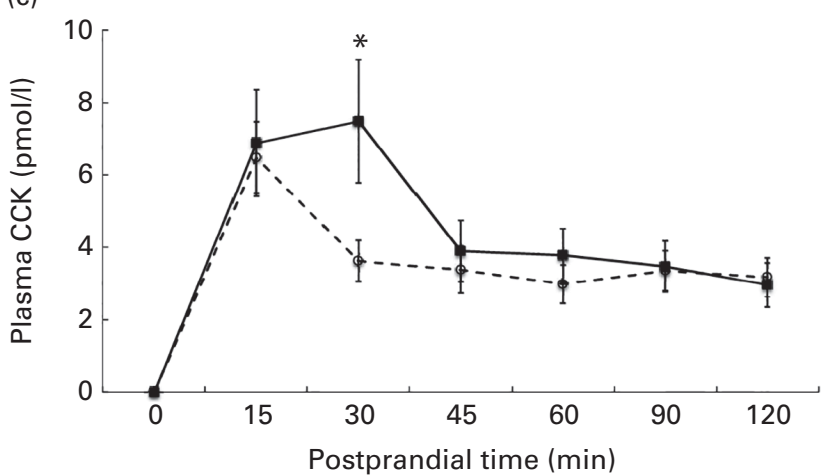

(b)

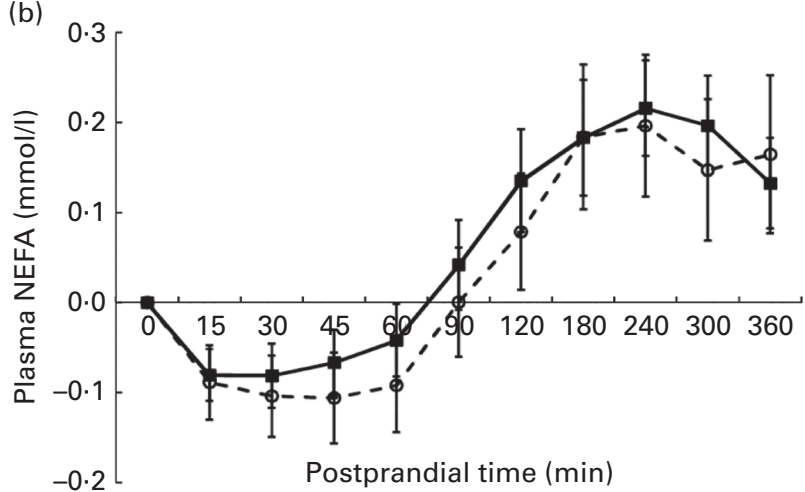

(d)

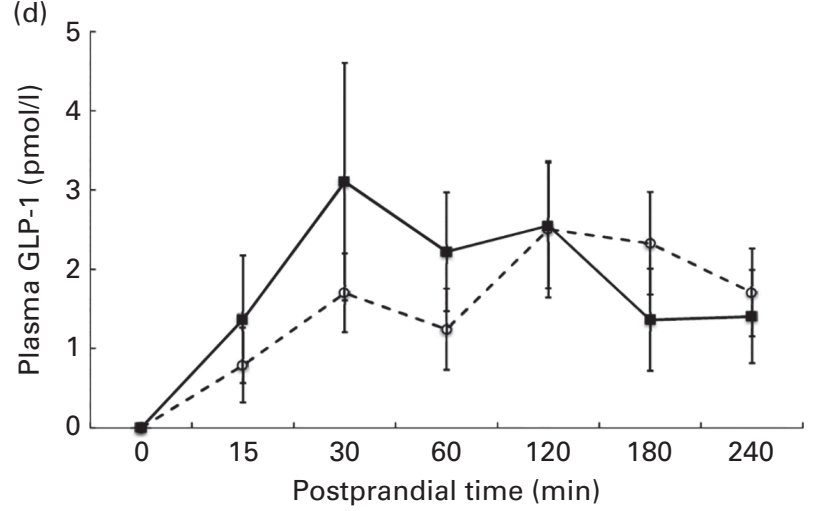

Fig. 2. Changes in the concentration of (a) serum TAG, (b) plasma NEFA, (c) plasma cholecystokinin (CCK) and (d) plasma glucagon-like peptide 1 (GLP-1) during the $360 \mathrm{~min}$ postprandial period in healthy young individuals consuming emulsions stabilised with either sodium caseinate (Cas; $-O-$ ) or transglutaminasecross-linked sodium caseinate (Cas-TG; $-\mathbf{-}-)$. Values are means $(n 15)$, with their standard errors represented by vertical bars. * Mean value was significantly different from that of the Cas meal condition $(P<0.05$; linear mixed-effects model)

protein from the surface of oil droplets ${ }^{(19)}$. Subsequently, the samples were heated in a water-bath $\left(70^{\circ} \mathrm{C}, 10 \mathrm{~min}\right)$ and loaded onto a $10 \%$ polyacrylamide NuPAGE Novex Bis-Tris precast gel $(10 \mu \mathrm{g}$ protein per well). After the heating, they were centrifuged at $9000 \boldsymbol{g}$ for $10 \mathrm{~min}$, and the resulting subnatant used for the SDS-PAGE analysis. Gels were run for $35 \mathrm{~min}$ at $120 \mathrm{~mA} / \mathrm{gel}$ and $200 \mathrm{~V}$. A continuous buffer system was used, consisting of $50 \mathrm{ml}$ of $20 \times$ NuPAGE MES SDS running buffer and $950 \mathrm{ml}$ of ultra-pure water. Afterwards, gels were stained using a colloidal Coomassie stain (SimplyBlue SafeStain). SeeBlue Plus2 (1X) prestained molecular-weight marker, comprising a mix of proteins ranging from a molecular weight of 3 to $188 \mathrm{kDa}$, was used. The emulsion characteristics are shown in Fig. 1.

\section{Appetite measurements}

Appetite ratings (hunger, satiety, desire to eat, fullness and thirst) and pleasantness of the test products were assessed using visual analogue scales. Each scale contained an unstructured $100 \mathrm{~mm}$ horizontal line with verbal anchors (in Finnish) at either end, expressing the weakest or strongest statement (i.e. 'I am not hungry at all' or 'I have never been hungrier'). Participants were instructed to draw a vertical line on the horizontal axis corresponding to their sensations at the time of assessment. Visual analogue scale ratings were measured in $\mathrm{mm}$, resulting in scores between 0 and 100 for statistical analyses.

\section{Biochemical measurements}

Plasma samples were collected in prechilled EDTA-containing tubes for insulin, CCK and GLP-1 analyses. Tubes containing fluoride citrate were used for plasma glucose samples. Plasma insulin, CCK and GLP-1 samples were centrifuged for $15 \mathrm{~min}$ at $1700 \mathrm{~g}$ and $4^{\circ} \mathrm{C}$. Plasma glucose samples were centrifuged for $10 \mathrm{~min}$ at $2400 \mathrm{~g}$ and $4^{\circ} \mathrm{C}$. All samples were immediately stored at $\left(-70^{\circ} \mathrm{C}\right.$ until analysed. Results were obtained from all the study participants, except for GLP-1 ( $n$ 14).

Plasma glucose sample was analysed using an enzymatic photometric assay (Konelab 20XTi Clinical Chemistry Analyzer; Thermo Electron Corporation) and plasma insulin using a luminometric immunoassay (ADVIA Centaur Immunoassay System; Siemens Medical Solutions Diagnostics). The intraassay CV for plasma glucose was $2 \cdot 7 \%$ at $10 \cdot 2 \mathrm{mmol} / \mathrm{l}$, and the inter-assay $\mathrm{CV}$ was $4.1 \%$ at $2.05 \mathrm{mmol} / \mathrm{l}$ and $1.8 \%$ at $8.2 \mathrm{mmol} / \mathrm{l}$. For plasma insulin, the intra-assay $\mathrm{CV}$ was $2.7 \%$ at $667 \mathrm{pmol} / \mathrm{l}$, and the inter-assay $\mathrm{CV}$ was $6.6 \%$ at $41 \mathrm{pmol} / 1$ and $5 \cdot 1 \%$ at $444 \mathrm{pmol} / 1$.

CCK RIA was performed using commercial RIA kits (EURIA CCK, catalogue no. RB 302; Euro Diagnostica). Plasma samples were extracted using solid-phase extraction cartridges 
(Sep-Pak ${ }^{\circledR}$ Vac/3cc (500 mg) C18 cartridges; Waters), as described previously ${ }^{(7)}$. Assay was done according to the manufacturer's instructions. Results were calculated with GraphPad Prism 6 (GraphPad Software, Inc.). The lowest detected value was $0.23 \mathrm{nmol} / \mathrm{l}$. The inter-assay $\mathrm{CV}$ of the EURIA CCK RB 302 kit was $13.7 \%$ at $4.2 \mathrm{pmol} / 1$ and $4.1 \%$ at $20.6 \mathrm{pmol} / 1$, and the intra-assay $\mathrm{CV}$ was $5.5 \%$ at $4.4 \mathrm{pmol} / 1$ and $2.0 \%$ at $20.6 \mathrm{pmol} / \mathrm{l}$.

A fluorometric enzyme immunoassay (ELISA; Linco Research, Inc.) was used to analyse plasma GLP-1 concentrations. The assay measures active GLP-1, i.e. GLP-1 1 -36amide and GLP- $1_{7-37}$. The inter-assay CV of the total GLP-1 ELISA kit was $28 \%$ at $2 \mathrm{pmol} / 1$ and $7 \cdot 5 \%$ at $42 \cdot 1 \mathrm{pmol} / 1$, and the intra-assay $\mathrm{CV}$ was $6.3 \%$ at $3.0 \mathrm{pmol} / 1$ and $4.4 \%$ at $13.3 \mathrm{pmol} / \mathrm{l}$.

Serum TAG and plasma NEFA concentrations were analysed using enzymatic colorimetric tests (Konelab 20XTi Clinical Chemistry Analyzer; Thermo Fisher Scientific). The intra-assay CV for the TAG measurement was $4.1 \%$, and the inter-assay CV was $2.5 \%$. For the NEFA measurement, the corresponding variations were 3.4 and $2.9 \%$.

\section{Statistical methods}

The study was powered based on the AUC of the baselinesubtracted plasma insulin concentration. If we assume a standard deviation of $1.2 \mu \mathrm{mol} \times \mathrm{min} / 1$ in the AUC, then a power of $90 \%$ is provided by fifteen participants.

SPSS for Windows software (version 19.0; SPSS, Inc.) was used to analyse the data. Results are expressed as means and standard errors of the mean, with $P \leq 0.05$ (two-sided) considered significant.

Linear mixed-effects modelling was used to compare the effects of the test emulsions on the profiles of postprandial metabolic, gastrointestinal hormone and appetite responses. In the analysis, the baseline value of each parameter was subtracted from the values of subsequent time points to take into account the possible effect of baseline differences on the analysis. In the analysis product, time and product $\times$ time was used as fixed factors and participant as a random factor. Linear mixed-effects modelling was also used to investigate the relationship between appetite and metabolic or hormonal responses. In the analysis, the test products and metabolic or hormonal responses were used as fixed factors and participant as a random factor. The AUC or the area above the curve was calculated using the trapezoidal rule to obtain the overall postprandial responses for the test products. Due to the skewed distribution of AUC and area above the curve variables, the differences between the test products were analysed using the non-parametric Wilcoxon test.

\section{Results}

\section{Serum TAG and plasma NEFA responses}

Postprandial serum TAG or plasma NEFA responses did not differ between the test emulsions (Fig. 2(a) and (b);
Table 4), with a time to peak of $2-3 \mathrm{~h}$ for serum TAG concentration and of $4 \mathrm{~h}$ for plasma NEFA concentration.

\section{Plasma cholecystokinin and glucagon-like peptide 1 responses}

Postprandial plasma CCK concentrations for the Cas-TG meal condition peaked at $30 \mathrm{~min}$ and then returned towards the baseline, whereas CCK concentrations for the Cas meal condition peaked at $15 \mathrm{~min}$ and decreased gradually during the postprandial period (Fig. 2(c)), with no significant difference between the peak values (Table 4). The CCK profiles were significantly different between the test emulsions at $30 \mathrm{~min}$ $(P<0 \cdot 05)$. The overall postprandial responses did not differ between the Cas-TG and Cas meal conditions (Table 4). GLP-1 responses did not differ significantly between the test emulsions (Fig. 2(d); Table 4).

Table 4. Appetite ratings and metabolic and gastrointestinal hormone responses, expressed as the area above the curve (AAC; satiety, fullness, TAG, NEFA, insulin, cholecystokinin (CCK) and glucagon-like peptide 1 (GLP-1)) or the AUC (hunger, desire to eat, thirst and glucose), with their peak/nadir values after the ingestion of the test emulsions

(Mean values with their standard errors, $n 15^{\star}$ )

\begin{tabular}{|c|c|c|c|c|c|}
\hline & \multicolumn{2}{|c|}{ Cas } & \multicolumn{2}{|c|}{ Cas-TG } & \multirow[b]{2}{*}{$P \dagger$} \\
\hline & Mean & SEM & Mean & SEM & \\
\hline \multicolumn{6}{|l|}{ Hunger } \\
\hline AUC & -4578 & 1565 & -2312 & 1094 & 0.023 \\
\hline Nadir & -30 & 7 & -16 & 5 & 0.039 \\
\hline \multicolumn{6}{|l|}{ Satiety } \\
\hline AAC & 6151 & 1838 & 3871 & 1409 & 0.084 \\
\hline Peak & 39 & 6 & 27 & 6 & 0.016 \\
\hline \multicolumn{6}{|l|}{ Fullness } \\
\hline AAC & 4361 & 1405 & 4568 & 1407 & 0.609 \\
\hline Peak & 29 & 6 & 33 & 6 & 0.191 \\
\hline \multicolumn{6}{|c|}{ Desire to eat } \\
\hline AUC & -3816 & 1161 & -2143 & 1034 & 0.023 \\
\hline Nadir & -29 & 6 & -21 & 7 & 0.078 \\
\hline \multicolumn{6}{|l|}{ Thirst } \\
\hline$A \cup C$ & -5223 & 1285 & -2594 & 1153 & 0.027 \\
\hline Nadir & -34 & 7 & -21 & 4 & 0.031 \\
\hline \multicolumn{6}{|l|}{ TAG } \\
\hline AAC & $109 \cdot 4$ & $28 \cdot 2$ & $102 \cdot 6$ & $22 \cdot 9$ & 0.910 \\
\hline Peak & 0.7 & 0.2 & 0.6 & 0.1 & 0.363 \\
\hline \multicolumn{6}{|l|}{ NEFA } \\
\hline AAC & $57 \cdot 6$ & $13 \cdot 7$ & $53 \cdot 5$ & $14 \cdot 2$ & 0.532 \\
\hline Peak & 0.3 & 0.1 & 0.3 & 0.1 & 0.306 \\
\hline \multicolumn{6}{|l|}{ Glucose } \\
\hline AUC & $-65 \cdot 3$ & 14.4 & -137.5 & $29 \cdot 6$ & 0.078 \\
\hline Nadir & -0.5 & 0.1 & -0.9 & 0.2 & 0.047 \\
\hline \multicolumn{6}{|l|}{ Insulin } \\
\hline AAC & 2955 & 1051 & 1402 & 406 & 0.281 \\
\hline Peak & 36 & 8 & 29 & 10 & 0.244 \\
\hline \multicolumn{6}{|l|}{ CCK } \\
\hline AAC & 369 & 53 & 449 & 77 & 0.156 \\
\hline Peak & 7 & 1 & 10 & 2 & 0.173 \\
\hline \multicolumn{6}{|l|}{ GLP-1 } \\
\hline AAC & 467.0 & $96 \cdot 6$ & 483.0 & $155 \cdot 9$ & 0.594 \\
\hline Peak & 4.4 & 0.8 & 4.4 & $1 \cdot 3$ & 0.594 \\
\hline
\end{tabular}

Cas, non-cross-linked sodium caseinate emulsion; Cas-TG, transglutaminasecross-linked sodium caseinate emulsion.

${ }^{*}$ Female, $n$ 14; male, $n 1$.

† Wilcoxon signed-rank test. 

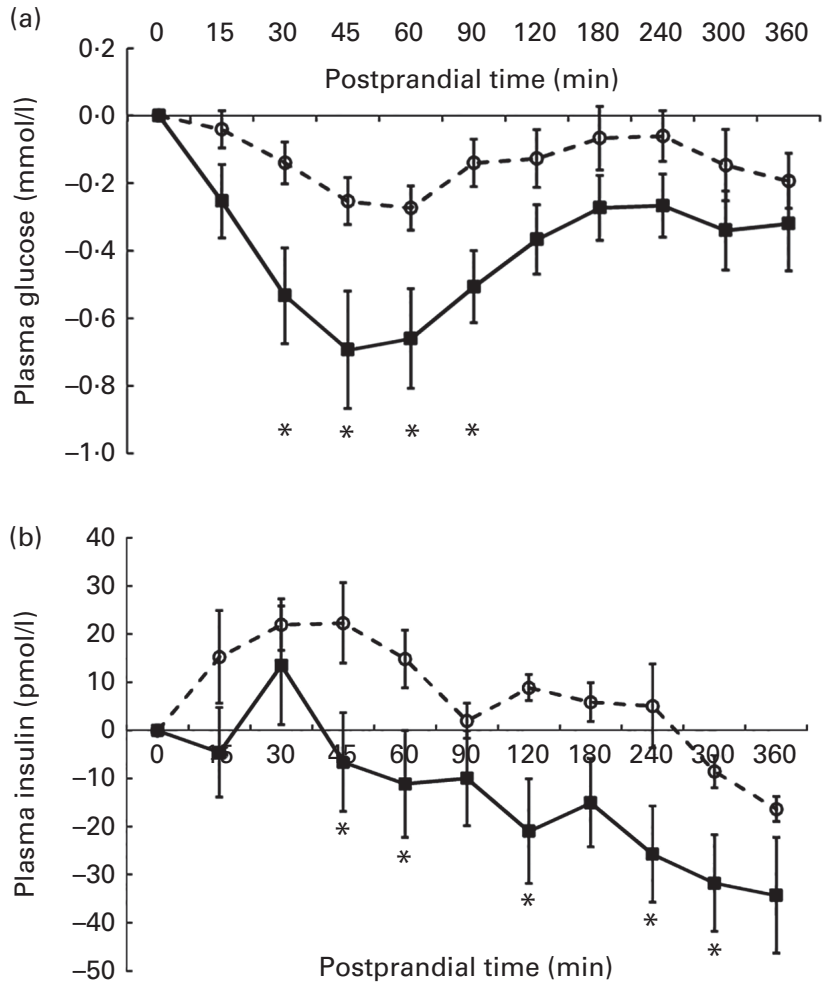

Fig. 3. Changes in the concentration of plasma (a) glucose and (b) insulin during the $360 \mathrm{~min}$ postprandial period in healthy young individuals consuming emulsions stabilised with either sodium caseinate (Cas; - $\bigcirc-$ ) or transglutaminase-cross-linked sodium caseinate (Cas-TG; - - -). Values are means $(n 15)$, with their standard errors represented by vertical bars. * Mean value was significantly different from that of the Cas meal condition $(P<0.05$; linear mixed-effects model).

\section{Plasma glucose and insulin responses}

After ingestion of both emulsions, postprandial plasma glucose concentrations decreased initially from the baseline concentration and reached a minimum after $45 \mathrm{~min}$ for the Cas meal condition and after $60 \mathrm{~min}$ for the Cas-TG meal condition, the nadir value being lower after the ingestion of Cas-TG than after the ingestion of Cas $(P<0.05$, Table 4). Thereafter, the concentrations gradually increased before declining again after $240 \mathrm{~min}$ (Fig. 3(a)). Significant differences between the profiles were observed at 30, 45, 60 and $90 \mathrm{~min}$, so that the glucose concentration was reduced more after the ingestion of Cas-TG than after the ingestion of Cas $(P<0 \cdot 05)$.

After the ingestion of Cas, two post-meal insulin upsurges were detected. The first increase peaked at $30-45 \mathrm{~min}$, after which the other peak was observed at about $180 \mathrm{~min}$. After the ingestion of Cas-TG, insulin concentration peaked at $30 \mathrm{~min}$ and then gradually decreased throughout the study period (Fig. 3(b)). Significant differences between the test emulsions were observed at 45, 60,120, 240 and $300 \mathrm{~min}$, so that the insulin concentration increased more after the ingestion of Cas than after the ingestion of Cas-TG at the given time points $(P<0.05)$. The overall postprandial insulin responses did not differ between the Cas-TG and Cas meal conditions (Table 4).

\section{Consumption of the test products and appetite ratings}

The mean time for ingestion of the test products was comparable: 1.65 (SEM 0.22) min for the Cas meal condition and 1.67 (SEM 0.23) min for the Cas-TG meal condition. There were no significant differences between the test emulsions in relation to the ratings of palatability.

Profiles of appetite sensations varied significantly over the experimental period $(P<0 \cdot 05$; Fig. 4(a) $-(\mathrm{e}))$. Hunger, desire to eat and thirst reached a minimum at $15-30 \mathrm{~min}$ after the ingestion of both emulsions and increased gradually thereafter. Feelings of fullness and satiety peaked at $15 \mathrm{~min}$ and declined progressively thereafter. The postprandial profiles for hunger, desire to eat and thirst differed significantly between the test emulsions; hunger was more reduced at 30 and $90 \mathrm{~min}$, desire to eat at $15,30,60,90$ and $180 \mathrm{~min}$, and thirst at 15, 30, 45, 60, 90, 120 and $180 \mathrm{~min}$ after the ingestion of Cas than after the ingestion of Cas-TG, respectively $(P<0.05)$. The overall postprandial responses were also significantly reduced after the ingestion of Cas than after the ingestion of Cas-TG, indicating a greater overall decrease in hunger, desire to eat and thirst between the two emulsions $(P<0.05$; Table 4). For hunger and thirst, the nadir values were significantly lower after the Cas than after Cas-TG $(P<0 \cdot 05$, Table 4$)$. Also, satiety profiles differed significantly between the test emulsions, so that satiety was more pronounced at 15, 30, 45, 60 and $90 \mathrm{~min}$ postprandially and peaked higher after the ingestion of Cas than after the ingestion of Cas-TG $(P<0.05$; Table 4). Fullness ratings did not differ significantly between the test emulsions.

\section{Relationship between appetite and metabolic/hormonal responses over time}

To investigate the relationship between appetite and metabolic/hormonal responses over time, graphs demonstrating the relationship between the responses at the same time points for each test product were generated. When the relationships with hunger and satiety responses were analysed, the test product $(P<0 \cdot 01)$ and plasma insulin $(P<0.001)$ and NEFA $(P<0.001)$ responses were significantly related to hunger (Fig. 5(a)-(d)), whereas plasma insulin $(P<0 \cdot 001)$, NEFA $(P<0 \cdot 001)$, CCK $(P<0.01)$ and test product $(P<0.01)$ responses were significantly associated with satiety (Fig. 6(a)-(f)).

\section{Gastric emptying rate}

The volume of gastric contents was measured both before and at ten time intervals after the ingestion of the test emulsions (Fig. 7). The measurements made at both 5 and $25 \mathrm{~min}$ after ingestion were very similar in both cases, suggesting that there was very little emptying from the gastric compartment in the first $25 \mathrm{~min}$ after consumption, regardless of the test emulsion. Subsequently, there was no significant difference in GE rates between the two test emulsions as both had $T_{1}$ values of $116 \mathrm{~min}$ based on the Elashoff equation ${ }^{(20)}$ $(P>0.05)$. The formation of layers due to phase separation 
of the emulsions in the stomach also appears to have been very similar. The images shown in Fig. 8 were obtained from a single volunteer 5 and $60 \mathrm{~min}$ after ingestion of the two test emulsions. All the four images show a brighter, denser, higher water content region at the base of the stomach, caused by phase separation of the test emulsions.

\section{Discussion}

The present clinical study showed that the TG-induced microstructural modification of the interfacial layer of a fat emulsion did not have a significant effect on the GE rate or overall postprandial lipid digestion after the ingestion of the test emulsion. However, the structuring of the emulsion interface affected early postprandial metabolic, hormonal and appetite responses as reflected by the increased appetite and suppressed satiety responses, as well as by the different postprandial glucose, insulin and CCK profiles. This indicates that nutrient-sensing mechanisms are operative, and even a subtle interfacial protein modification is capable of modifying postprandial physiological and appetite responses.

In the present study, the GE rate was measured by MRI, and as in previous studies using this technique ${ }^{(13-15)}$, the images showed signs of phase separation for the two emulsions occurring during the gastric phase, caused by the density difference between the oil and aqueous phases and accelerated by flocculation of the protein due to low $\mathrm{pH}$. This is in agreement with previous studies showing that casein can be considered as a slow-release milk protein because of its sensitivity to acid coagulation ${ }^{(21,22)}$. A recent in vitro study using test emulsions of comparable composition and characteristics with the ones used in the present study demonstrated that TG-induced structuring of the emulsion interface increased resistance to proteolysis and thus enhanced emulsion stability under gastric conditions ${ }^{(23)}$. This behaviour would make Cas-TG less prone to acid coagulation than Cas. The effect was shown to be due to strengthening of the casein interfacial layer at the oil/water interface including aggregation of the protein in the layer coating the oil droplets. The in vitro study also showed that the test emulsions were very similar, producing evenly sized oil droplets and similar digestion products, suggesting that the GE rate would not be significantly affected, although very different rates of proteolysis were observed. Furthermore, the in vivo MRI images obtained in the present study showed signs of comparable phase separation for the two emulsions during the gastric phase, which was probably the reason for the similar GE rates after the consumption of the test emulsions. Previously, it has been shown that inhibition of marked phase separation ${ }^{(14,15)}$ and/or (lack of) subsequent duodenal feedback ${ }^{(24)}$ is needed to slow down the GE rate significantly, indicating that these factors are powerful enough to affect gastric motor function after the ingestion of emulsions with different characteristics.

The results on postprandial TAG responses suggest that the overall lipid digestion during the intestinal phase was not markedly affected by TG-induced interfacial structuring. Although the intestinal content (e.g. droplet size, lipolysis products, lipase and bile salt concentrations) was not sampled for further analysis in the present study, it is likely that the structuring of the interfacial layer did not affect markedly the functioning of these key factors known to affect lipid digestion $^{(3,16,25)}$. Therefore, it can be presumed that the rate of lipid digestion and absorption during the intestinal phase was equally efficient, and resulted in serum TAG responses with similar amplitudes after the ingestion of the two test emulsions. Thus, in contrast to our hypothesis, the TGinduced structuring of the interfacial layer was not strong enough to markedly delay the overall lipid digestion process.
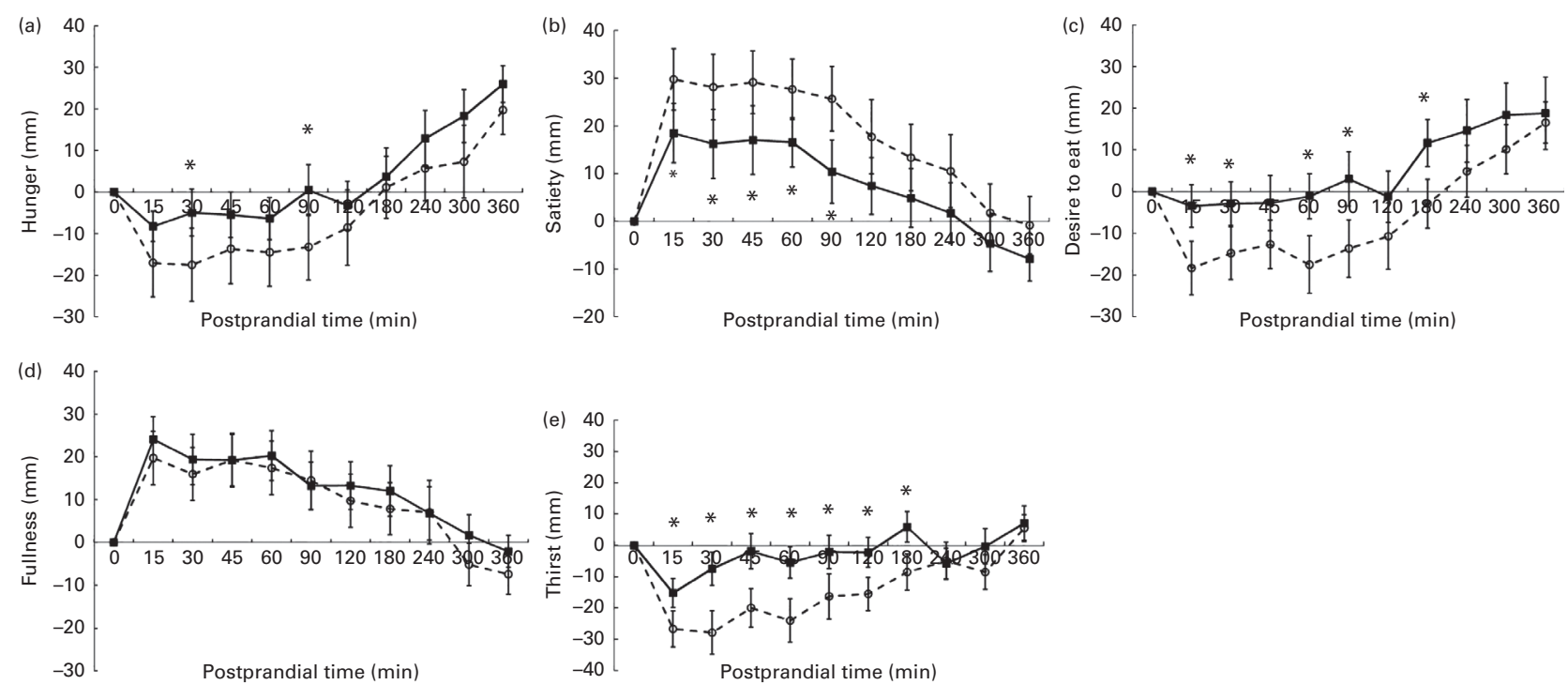

Fig. 4. Changes in visual analogue scale ratings for (a) hunger, (b) satiety, (c) desire to eat, (d) fullness and (e) thirst during the 360 min postprandial period in healthy young individuals consuming emulsions stabilised with either sodium caseinate (Cas; - - -) or transglutaminase-cross-linked sodium caseinate (Cas-TG; - - -). Values are means ( $n$ 15), with their standard errors represented by vertical bars. * Mean value was significantly different from that of the Cas meal condition $(P<0.05$; linear mixed-effects model). 
(a)

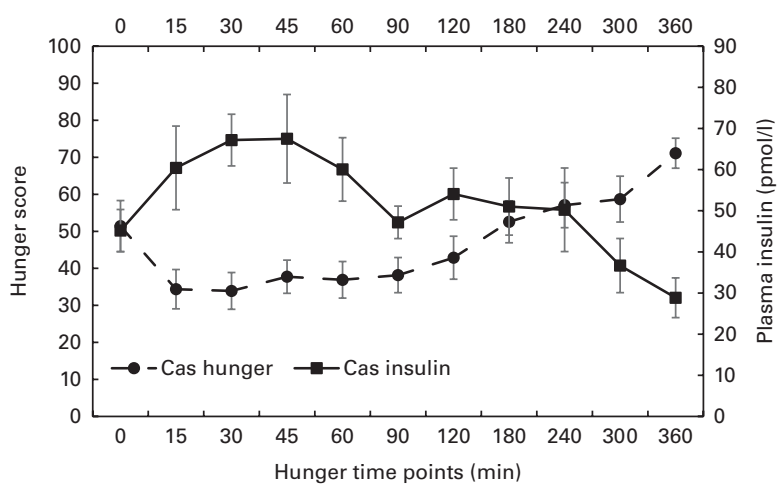

(c)

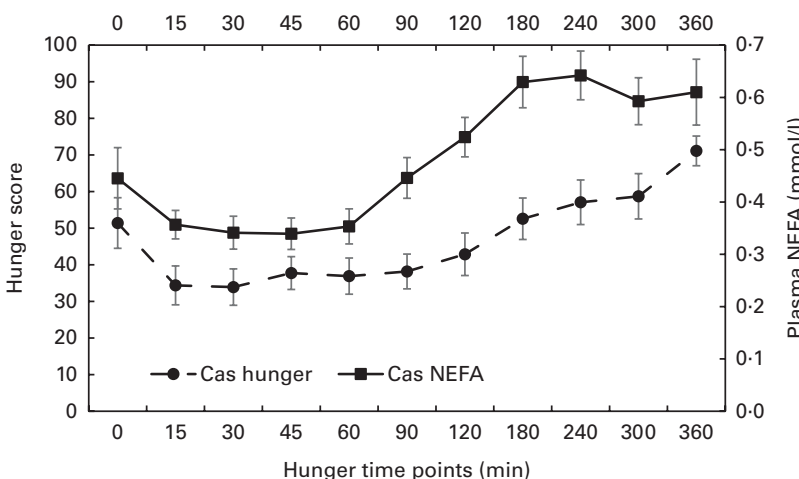

(b)

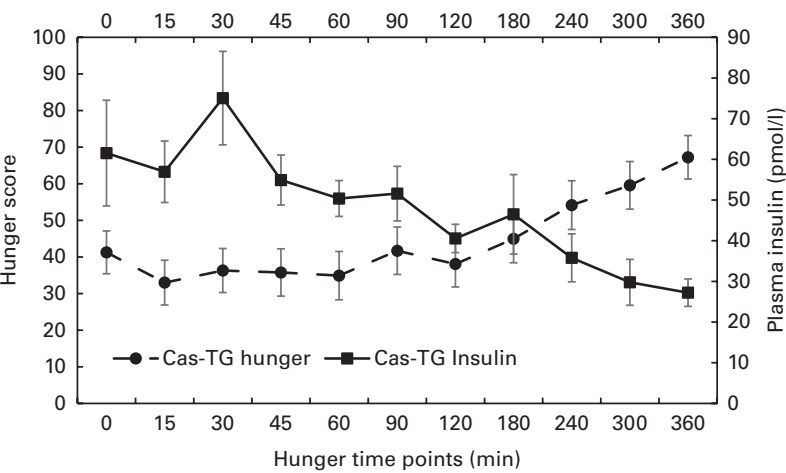

(d)

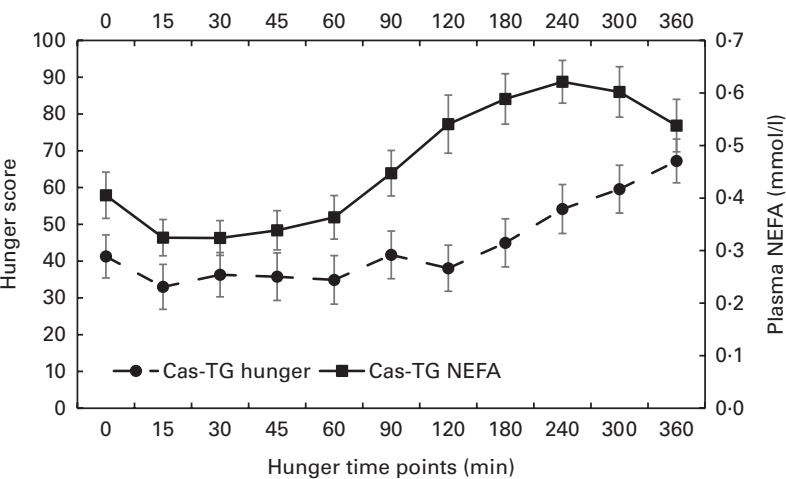

Fig. 5. Hunger scores (visual analogue scales) synchronised with plasma $(a, b)$ insulin and (c, d) NEFA concentrations in the Cas (non-cross-linked sodium caseinate emulsion) and Cas-TG (transglutaminase-cross-linked sodium caseinate emulsion) meal conditions. Values are means $(n 15)$, with their standard errors represented by vertical bars.

As demonstrated previously, appetite sensations are affected by different emulsion properties ${ }^{(14-16,26)}$, of which phase separation tendency during the gastric phase ${ }^{(14,15)}$ and droplet size ${ }^{(16,26)}$ have been shown to be influential. In these studies, the effects on appetite were probably due to the differences in the behaviour of emulsions during the gastric phase. In the present study, hunger and desire to eat were significantly less reduced and satiety less increased after the ingestion of Cas-TG compared with Cas. It is possible that if the protein digestion process was decreased in the early postprandial phase due to cross-linking, the alterations in protein and fat digestion may have been reflected by increased
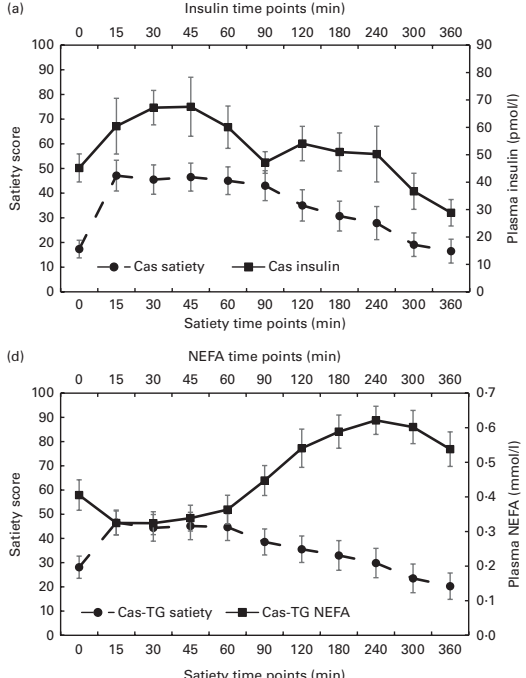
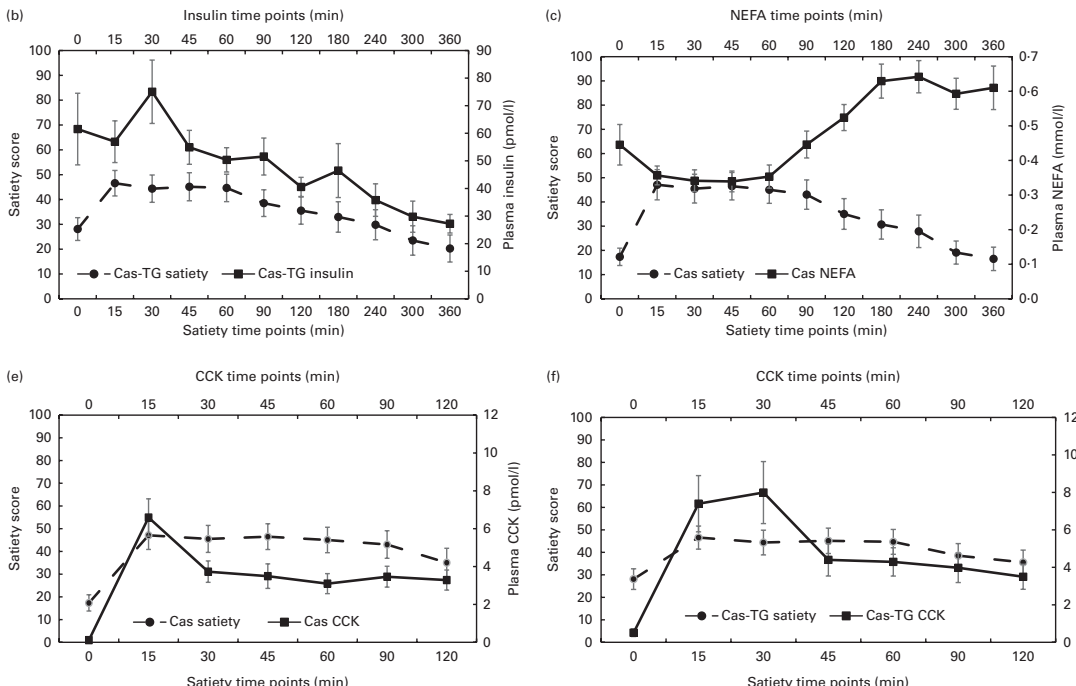

Fig. 6. Satiety scores (visual analogue scales) synchronised with plasma (a, b) insulin, (c, d) NEFA and (e, f) cholecystokinin (CCK) concentrations in the Cas (non-cross-linked sodium caseinate emulsion) and Cas-TG (transglutaminase-cross-linked sodium caseinate emulsion) meal conditions. Values are means ( $n$ 15), with their standard errors represented by vertical bars. 


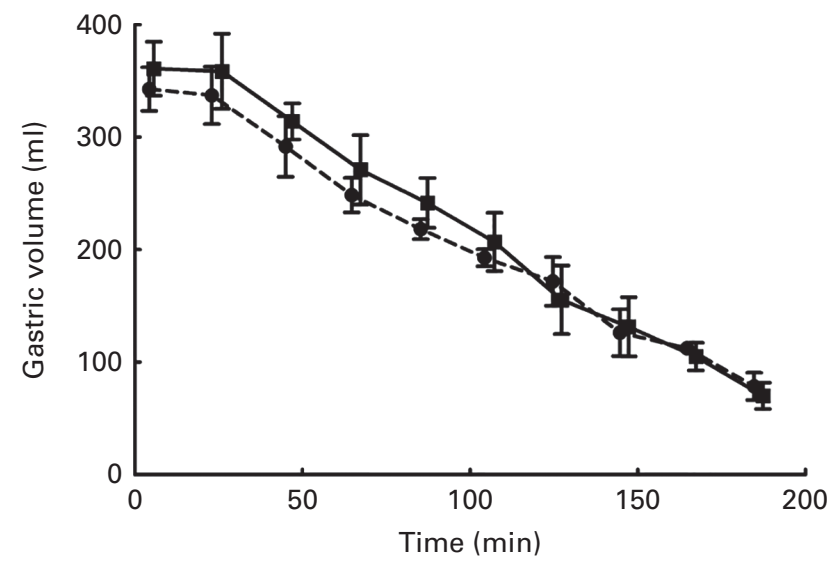

Fig. 7. Volume of gastric contents during the $180 \mathrm{~min}$ postprandial period in individuals consuming emulsions stabilised with either sodium caseinate (Cas; - -) or transglutaminase-cross-linked sodium caseinate (Cas-TG; $-\mathbf{-}-$ ). Values are means $(n 3)$, with their standard errors represented by vertical bars.

hunger/desire to eat and decreased satiety after the Cas-TG due to reduced or delayed satiety-stimulating mechanisms. The present results on less decreased appetite after the ingestion of Cas-TG are parallel to those from studies reporting that fat digestion was slower/delayed due to gastric phase separation ${ }^{(15)}$ and increased droplet size $^{(16,26)}$, or inhibited $^{(27-29)}$, which was subsequently reflected by increased hunger or appetite responses.

Even though the test emulsions did not contain any carbohydrate, postprandial glucose and insulin profiles varied over the experimental period and differed between the test emulsions. The glucose and insulin profiles suggest that protein and lipid components were released from Cas-TG in a lower rate during the early postprandial phase when compared with Cas. Plasma glucose concentration decreased slightly but significantly more after the ingestion of Cas-TG than after the ingestion of Cas. At the same time, circulating insulin concentration was less stimulated after the ingestion of Cas-TG. As the GE rate was comparable between the test emulsions, the difference observed in the glucose and insulin profiles most probably resulted from the different release and/ or absorption rates of the nutrients during the small intestinal phase due to the different initial digestion behaviours of the test emulsions. It is also possible that not only the protein released from the interfacial layer of the emulsified lipid droplets, but also the dispersed cross-linked and non-cross-linked protein in the continuous phase contributed to glucose and insulin responses. It is well known that amino acids and fatty acids release incretins ${ }^{(30)}$, and have a stimulating effect on insulin secretion ${ }^{(31,32)}$

The postprandial secretion of CCK and GLP-1 was stimulated after the two emulsions, but only the CCK profile differed markedly between the emulsions, showing a stronger increase after the ingestion of Cas-TG than after the ingestion of Cas. However, since the overall postprandial CCK response did not differ between the emulsions, it could be that the single peak in the CCK profile after the ingestion of Cas-TG was too weak to stimulate stronger satiety sensation compared with Cas. It is also possible that we failed to detect the initial CCK peak after the ingestion of Cas $\left(<15 \min ^{(17,33,34)}\right)$. If Cas peaked earlier than Cas-TG, it would also explain the more attenuated hunger responses after consuming Cas compared with Cas-TG. The postprandial GLP-1 response showed a trend towards higher levels for Cas-TG in the first $30 \mathrm{~min}$, although the difference was not significant between the emulsions for the overall response. GLP-1 is secreted from the $\mathrm{L}$ cells in the distal intestine, and therefore it is probable that the difference in the initial digestion phase of the emulsions was not marked enough to stimulate differently the early postprandial GLP-1 secretion. Furthermore, the marked individual variation in postprandial GLP-1 secretion presumably resulted in non-significant differences between the GLP-1 responses after consuming Cas and Cas-TG. Thus, both CCK and GLP-1 responses indicate that protein and lipid components that were released from the emulsions stimulated subsequently the secretion of these hormones. Furthermore, it has been shown that hydrolysis of fat is a critical step for fat-induced stimulation of GLP-1 in humans, and the signal is mediated via CCK release ${ }^{(35)}$

When analysing the relationships between appetite and metabolic or hormonal responses over time, plasma insulin and NEFA responses were strongly related to hunger and satiety. Insulin contributed to decreased hunger and increased satiety, especially during the initial postprandial phase. Instead, the relationship of NEFA with hunger and satiety was most evident during the later postprandial phase, and the relationship with hunger and satiety being the opposite with that of insulin. CCK and satiety responses were also positively related, in line with the well-known role of CCK as a satiety hormone ${ }^{(36-38)}$. Thus, it could be argued that the different appetite responses observed in the present study were mediated by these metabolites and hormones, and therefore insulin and NEFA together with CCK could be considered important metabolic mediators of postprandial appetite, as suggested previously ${ }^{(37,39)}$.

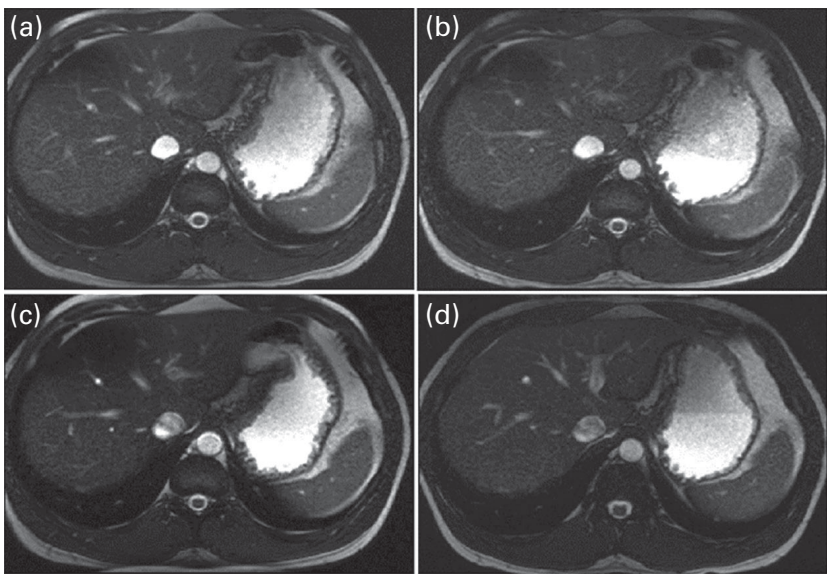

Fig. 8. MRI images of the abdomen of a recumbent volunteer at $5 \mathrm{~min}(\mathrm{a}, \mathrm{b})$ or $60 \mathrm{~min}$ (c, d) after consuming emulsions stabilised with either sodium caseinate $(\mathrm{a}, \mathrm{c})$ or transglutaminase-cross-linked sodium caseinate $(\mathrm{b}, \mathrm{d})$. The stomach is shown on the right of the images. 
In conclusion, the present results suggest that even a subtle structural modification of the interfacial layer of a fat emulsion can alter the early postprandial profiles of glucose, insulin, CCK, appetite and satiety through decreased protein digestion without affecting significantly on GE or the overall digestion of lipids under physiological conditions in human subjects. These results emphasise the key role of the interfacial layer of emulsions in controlling postprandial physiological responses.

\section{Acknowledgements}

The authors acknowledge Eeva Lajunen, Taisa Venäläinen and Emma Kakkonen for their excellent technical and laboratory assistance throughout the study.

The present study was supported by the Academy of Finland (TEPESS consortium - grant no. 118281, 118191 and 216327), Academy Professorship (K. S. P., grant no. 131460), The Finnish Graduate School on Applied Bioscience: Bioengineering, Food Nutrition, Environment, and Kuopio University Hospital (EVO funding). The work at the IFR was supported by the BBSRC through research grant BB/J004545/1. The MRI was funded by the NNUH Radiology Department research budget. The funders had no role in the design and analysis of the study or in the writing of this article.

The authors' contributions are as follows: K. R. J., A. M., L. J. K., M. E. L., K.-H. H., D. E. L., L. K. N., H. M. M., A. R. M., C. E. N. M. and K. S. P. designed the research; K. R. J. conducted the research; A. M., M. E. L. and A. R. M. provided the ingredients and the protocol for preparing the test products; K. R. J. analysed the data and wrote the first version of the manuscript. All authors contributed to the writing of the final manuscript.

K. R. J., K.-H. H., A. M. and A. R. M. are participants in the FA1005 COST Action INFOGEST on food digestion.

There are no conflicts of interest.

\section{References}

1. Westerterp-Plantenga MS (2004) Fat intake and energybalance effects. Physiol Behav 83, 579-585.

2. Maljaars PW, Peters HP, Mela DJ, et al. (2008) Ileal brake: a sensible food target for appetite control. A review. Physiol Behav 95, 271-281.

3. McClements DJ, Decker EA \& Park Y (2009) Controlling lipid bioavailability through physicochemical and structural approaches. Crit Rev Food Sci Nutr 49, 48-67.

4. Singh H \& Sarkar A (2011) Behaviour of protein-stabilised emulsions under various physiological conditions. Adv Colloid Interface Sci 165, 47-57.

5. Mackie A \& Macierzanka A (2010) Colloidal aspects of protein digestion. Curr Opin Colloid Interface Sci 15, 102-108.

6. Buchert J, Ercili Cura D, Ma H, et al. (2010) Crosslinking food proteins for improved functionality. Annu Rev Food Sci Technol 1, 113-138.

7. Juvonen KR, Karhunen LJ, Vuori E, et al. (2011) Structure modification of a milk protein-based model food affects postprandial intestinal peptide release and fullness in healthy young men. Br J Nutr 106, 1890-1898.
8. Juvonen KR, Lille ME, Laaksonen DE, et al. (2012) Crosslinking with transglutaminase does not change metabolic effects of sodium caseinate in model beverage in healthy young individuals. Nutr J 11, 35 .

9. Mun S, Decker EA \& McClements DJ (2007) Influence of emulsifier type on in vitro digestibility of lipid droplets by pancreatic lipase. Food Res Int 40, 770-781.

10. Reis PM, Raab TW, Chuat JY, et al. (2008) Influence of surfactants on lipase fat digestion in a model gastro-intestinal system. Food Biophysics 3, 370-381.

11. Hur SJ, Decker EA \& McClements DJ (2009) Influence of initial emulsifier type on microstructural changes occurring in emulsified lipids during in vitro digestion. Food Chem 114, 253-262.

12. Marciani L, Wickham M, Hills BP, et al. (2004) Intragastric oil-in-water emulsion fat fraction measured using inversion recovery echo-planar magnetic resonance imaging. $J$ Food Sci 69, E290-E296.

13. Marciani L, Wickham MS, Bush D, et al. (2006) Magnetic resonance imaging of the behaviour of oil-in-water emulsions in the gastric lumen of man. Br J Nutr 95, 331-339.

14. Marciani L, Wickham M, Singh G, et al. (2007) Enhancement of intragastric acid stability of a fat emulsion meal delays gastric emptying and increases cholecystokinin release and gallbladder contraction. Am J Physiol Gastrointest Liver Physiol 292, G1607-G1613.

15. Marciani L, Faulks R, Wickham MS, et al. (2009) Effect of intragastric acid stability of fat emulsions on gastric emptying, plasma lipid profile and postprandial satiety. Br J Nutr 101, 919-928.

16. Seimon RV, Wooster T, Otto B, et al. (2009) The droplet size of intraduodenal fat emulsions influences antropyloroduodenal motility, hormone release, and appetite in healthy males. Am J Clin Nutr 89, 1729-1736.

17. Foltz M, Maljaars J, Schuring EA, et al. (2009) Intragastric layering of lipids delays lipid absorption and increases plasma CCK but has minor effects on gastric emptying and appetite. Am J Physiol Gastrointest Liver Physiol 296, G982-G991.

18. Stunkard AJ \& Messick S (1985) The three-factor eating questionnaire to measure dietary restraint, disinhibition and hunger. $J$ Psychosom Res 29, 71-83.

19. Macierzanka A, Bordron F, Rigby NM, et al. (2011) Transglutaminase cross-linking kinetics of sodium caseinate is changed after emulsification. Food Hydrocoll 25, 843-850.

20. Elashoff JD, Reedy TJ \& Meyer JH (1982) Analysis of gastricemptying data. Gastroenterology 83, 1306-1312.

21. Hall WL, Millward DJ, Long SJ, et al. (2003) Casein and whey exert different effects on plasma amino acid profiles, gastrointestinal hormone secretion and appetite. Br J Nutr 89, 239-248.

22. Veldhorst MAB, Nieuwenhuizen AG, HochstenbachWaelen A, et al. (2009) Dose-dependent satiating effect of whey relative to casein or soy. Physiol Behav 96, 675-682.

23. Macierzanka A, Böttger F, Rigby NM, et al. (2012) Enzymatically structured emulsions in simulated gastrointestinal environment: impact on interfacial proteolysis and diffusion in intestinal mucus. Langmuir 28, 17349-17362.

24. Keogh JB, Wooster TJ, Golding M, et al. (2011) Slowly and rapidly digested fat emulsions are equally satiating but their triglycerides are differentially absorbed and metabolized in humans. J Nutr 141, 809-815.

25. Armand M, Pasquier B, André M, et al. (1999) Digestion and absorption of 2 fat emulsions with different droplet sizes in the human digestive tract. Am J Clin Nutr 70, 1096-1106. 
26. Maljaars PW, van der Wal RJ, Wiersma T, et al. (2012) The effect of lipid droplet size on satiety and peptide secretion is intestinal site-specific. Clin Nutr 31, 535-542.

27. Feinle C, Rades T, Otto B, et al. (2001) Fat digestion modulates gastrointestinal sensations induced by gastric distention and duodenal lipid in humans. Gastroenterology 120, 1100-1107.

28. Feinle C, O'Donovan D, Doran S, et al. (2003) Effects of fat digestion on appetite, APD motility, and gut hormones in response to duodenal fat infusion in humans. Am J Physiol Gastrointest Liver Physiol 284, G798-G807.

29. Ellrichmann M, Kapelle M, Ritter PR, et al. (2008) Orlistat inhibition of intestinal lipase acutely increases appetite and attenuates postprandial glucagon-like peptide-1-(7-36)amide-1, cholecystokinin, and peptide YY concentrations. J Clin Endocrinol Metab 93, 3995-3998.

30. Carr RD, Larsen MO, Winzell MS, et al. (2008) Incretin and islet hormonal responses to fat and protein ingestion in healthy men. Am J Physiol Endocrinol Metab 295, E779-E784.

31. Nolan CJ, Madiraju MS, Delghingaro-Augusto V, et al. (2006) Fatty acid ÿignalling in the $\beta$-cell and insulin secretion. Diabetes 55, Suppl. 2, S16-S23.

32. Gannon MC \& Nuttall FQ (2010) Amino acid ingestion and glucose metabolism - a review. IUBMB Life 62, 660-668.
33. Liddle RA, Goldfine ID, Rosen MS, et al. (1985) Molecular forms, responses to feeding, and relationship to gallbladder contraction. Cholecystokinin bioactivity in human plasma. J Clin Invest 75, 1144-1152.

34. Ellrichmann M, Ritter PR, Otte JM, et al. (2007) Orlistat reduces gallbladder emptying by inhibition of CCK release in response to a test meal. Regul Pept 139, 136-140.

35. Beglinger S, Drewe J, Schirra J, et al. (2010) Role of fat hydrolysis in regulating glucagon-like peptide-1 secretion. $J$ Clin Endocrinol Metab 95, 879-886.

36. Kissileff HR, Pi-Sunyer FX, Thornton J, et al. (1981) C-terminal octapeptide of cholecystokinin decreases food intake in man. Am J Clin Nutr 34, 154-160.

37. Lieverse RJ, Jansen JB, Masclee AM, et al. (1994) Satiety effects of cholecystokinin in humans. Gastroenterology 106, 1451-1454.

38. Beglinger C, Degen L, Matzinger D, et al. (2001) Loxiglumide, a CCK-A receptor antagonist, stimulates calorie intake and hunger feelings in humans. Am J Physiol Regul Integr Comp Physiol 280, R1149-R1154.

39. Tataranni PA, Gautier JF, Chen K, et al. (1999) Neuroanatomical correlates of hunger and satiation in humans using positron emission tomography. Proc Natl Acad Sci US A 13, 4569-4374. 